\title{
Weaving a Web Development Curriculum
}

\author{
Wayne A Haga and Janos T Fustos \\ Metropolitan State College, Denver, CO, USA
}

haga@mscd.edu fustos@mscd.edu

\begin{abstract}
Faculty in the Computer Information Systems department at the authors' institution is in the process of developing a new Computer Information Systems degree with several areas of emphasis. One of the proposed areas of emphasis will be to prepare students for a career as a web developer. As part of the curriculum development process, the authors collected data regarding the current demand for web developers, the education level requested, salaries, and the specific skills employers are demanding. The research process included reading and recording the education level, experience, and specific skills employers are requesting for hundreds of jobs that have been posted on the Internet within the last few months. Additionally, data was gathered from other sources including courses and programs offered at other institutions of higher education. Using this data, a model curriculum for a degree leading to a career in the field of web development is proposed.
\end{abstract}

Keywords: education, model, curriculum, web developer, job requirement

\section{The Web Developer}

\section{The Role of a Web Developer}

Different organizations define the role and the position of the web developer quite differently. Unfortunately, there is no Department of Labor (DOL) definition for this occupation that might clarify the very colorful palette.

Mozzila.org defines the web developers as "people who write web pages" (Mozilla, 2002). The online Web Developer's Journal defines the web developer as "a person who not only designs web sites, but also understands the web as a medium, and is able to translate that understanding into site design." The World Organization of Webmasters specifies the Web developers in its certification program as professionals who "... are proficient at creating web site structure and interactivity. They use database tools and custom applications to prepare the site for dynamic presentation of content to the visitor." In several cases the job descriptions might also be mixed with the tasks and the responsibilities of a web administrator/webmaster and/or a web designer.

\section{Job Demand for Web Developers}

Material published at of $n$-line or in print, is copyrighted by Informing Science. Permission to make digital or paper copy of part or all of these works for personal or classroom use is granted without fee provided that the copies are not made or distributed for profit or commercial advantage AND that copies 1) bear this notice in full and 2) give the full citation on the first page. It is permissible to abstract these works so long as credit is given. To copy in all other cases or to republish or to post on a server or to redistribute to lists requires specific permission

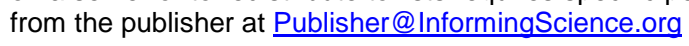

The U.S. Department of Labor in the Issues in Labor Statistics newsletter (December 06, 2001) listed the Webmasters, the Web designers and Web developers among the new and emerging occupations. (See Figure 1.) They also stated "Within the Internet occupations, more new occupations were related to such 
Figure 1: Functional Specialties in Web-Related Jobs

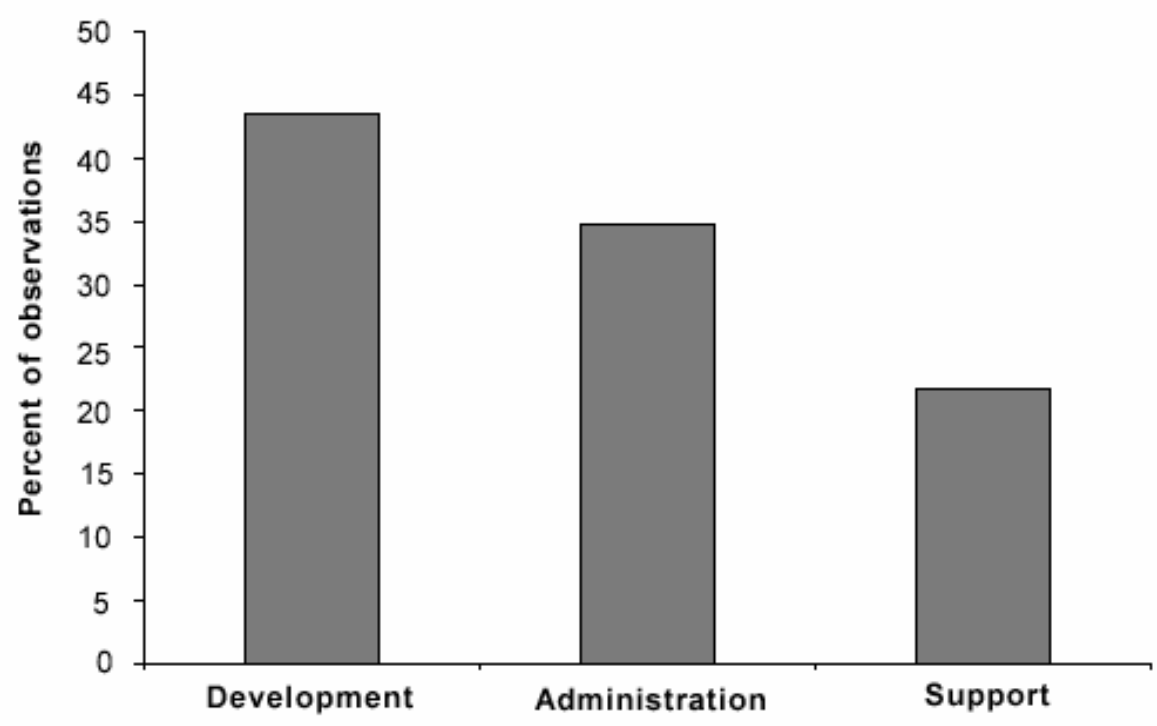

Source: IJ.S. Denartment of Iahor (2001)

Web site development tasks than to either site administration or support."

The authors searched for job advertisement in online Web job/career search engines. For the keywords we used: web \& developer (Boolean AND connection), the scope was the whole country, and the time frame the last 30 days/4 weeks.

The results are presented in Table 1 .

Table 1: Number of Online Advertisements for Web developers

\begin{tabular}{|l|c|}
\hline \multicolumn{1}{|c|}{ Site } & \# of Advertisements \\
\hline dice.com & 3661 \\
\hline monster.com & 952 \\
\hline careerpath.com & 598 \\
\hline recruitersonline.com & 239 \\
\hline headhunter.com & 589 \\
\hline jobsearchengine.com & 500 \\
\hline hotjobs.com & 487 \\
\hline jobsearch.org & 857 \\
\hline
\end{tabular}




\section{Salaries for Web Developers}

The Bureau of Labor Statistics does not have a separate category for Web/Internet related jobs. The closest white-collar professional and technical areas are the computer systems analysts and scientists, and the operations/systems researchers and analysts. The reported salaries for these computer related non-research occupations are between $\$ 26.26$ and $\$ 34.08$ (hourly mean), and $\$ 54,630$ and $\$ 70,890$ (annual mean) (U.S. BLS, 2001). Many companies just state that they offer competitive salaries (whatever that means), or state that the salary will be based on experience and skills that the candidate offers.

Of 351 job position announcements examined for this study, only 63 listed salary levels or ranges. For positions with ranges, the average of the salary range was recorded. The salary range for all positions was from $\$ 10,400$ to $\$ 250,000$ with the average being $\$ 70,674$. The median salary offered was $\$ 64,000$ and the $25^{\text {th }}$ and $75^{\text {th }}$ percentiles $\$ 52,000$ and $\$ 80,000$, respectively.

\section{Formal Education Requirements for a Web Developer}

Of 351 job position announcements examined for this study, the majority (255) listed no specific formal educational requirements. Forty-eight listed only a high school degree as the minimum education required for the position. Five required at least an associate (2-year) degree. Forty positions required at least a bachelors degree (preferably in Computer Science, Computer Information Systems, or Management Information Systems). Only three required an advanced Masters degree. It was apparent from the job descriptions that employers were more interested in the Web Development skills the applicant possessed, rather than how the person had obtained those skills.

\section{What Does It Take to Become a Successful Web Developer?}

The following categories of requisite knowledge and skills are necessary for a Web developer:

Knowledge:

- Computers and networking including different platforms and protocols.

- Communications and media - knowledge of electronic media production, communication, and dissemination techniques and methods.

- Telecommunications - knowledge of transmission, broadcasting, switching, control, and operation of telecommunications systems.

Skills:

- Programming - writing server side and client side application programs for various purposes by using different programming languages.

- Web page design and development - create static and dynamic web pages with text and graphical content in different developing environments by using authoring tools.

- Visual design of Web pages with graphical and multimedia applications.

- Integration database functions in the Web services, and the extension of Web functionality.

- Adding security services to the Web servers, perform administration tasks in site configuration, management, and maintenance.

- Web communication: writing and editing for the Web. 


\section{What Do Employers Want?}

A search for jobs with "Web Developer" in the job title was performed at America's Job Bank (http://www.jobsearch.org). This site allows you to search for jobs listed at all 50 of the state government job service organizations. An initial search resulted in 857 matches. Many of these turned out to be duplicate listings. It was decided that examining between 300 and 400 jobs descriptions (after eliminating duplicates) would be adequate to get a representative sample. All jobs were listed with the agencies during the months of February and March of 2002. After elimination of obvious duplicate job listings, 351 positions were included in this study.

Job descriptions/requirements for the 351 jobs were examined. Forty (11\%) of the positions listed either no requirements or only a list of generic skills such as:

- experience as a web developer

- $\quad$ strong technical skills

- $\quad$ strong problem solving skills

- $\quad$ strong writing skills

- $\quad$ strong communication skills

- project management skills

- teamwork skills

- leadership

- troubleshooting skills

Of the remaining 311 positions, the technical skills required/requested were noted and tallied. Since the purpose of this study was to help develop a curriculum in web page development with the skills that industry wanted, skills requested were recorded regardless of whether the skill was required or preferred.

One hundred and sixty of the positions specified the number of years experience required for the positions. The average number years of experience requested ranged from 1 to 10 years, with the average being 3.8 years.

Initially, 75 positions were examined, and a complete list of skills required/preferred was noted. Skills were then categorized. Skills were next broken into the 15 following categories:

1. Markup language (HTML, UML, DHTML)

2. Web authoring tools (Flash, FrontPage, Photoshop)

3. Client side scripting (Javascript, VBscript, XSL, XSLT, CSS, generic request for scripting skills)

4. Client side scripting products (Dreamweaver, Generator, WebLogic)

5. Server side scripting (ASP, JSP/EJB, Perl, servlets/EJB, generic)

6. Server side scripting products (Cold Fusion, ISAPI, NSAPI)

7. Programming languages (Active $\mathrm{X}, \mathrm{C} / \mathrm{C}++, \mathrm{CICS} / \mathrm{COBOL}$, Java, J++, Visual Basic, generic)

8. Programming products ( Jbuilder, Interdeveloper, Visual Studio, Visual Age)

9. Database (SQL, XML, ODBC, JDBC, DDL, generic) 
10. Database products (Oracle/PL/SQL), DB2, Informix, MS Access, PowerBuilder, Sysbase, MS Transaction Server)

11. Operating systems (Unix, Linux, Windows, Solaris, Mac OS, OS400)

12. Methodology (COM/DCOM, OOP/OOD, RAD/JAD, SDLC, Database/E-R modeling/normalization)

13. General server experience (Apache, IIS, Websphere, MS Commerce)

14. General networking skills

15. General e-commerce skills

Table 2 summarizes the number and percentage for each category where at least one of the skills was requested and/or required. The most requested skills were server side scripting (70\%), programming languages $(68 \%)$, database $(55 \%)$, database products $(55 \%)$, markup languages $(51 \%)$, and client side scripting $(46 \%)$.

Table 2. Skill Areas Requested ( $\mathrm{N}=311)$

\begin{tabular}{|l|r|r|}
\hline \multicolumn{1}{|c|}{ Category } & \multicolumn{1}{c|}{ n } & \multicolumn{1}{c|}{$\%$} \\
\hline Markup Languages & 160 & $51 \%$ \\
\hline Web Authoring Tools & 34 & $11 \%$ \\
\hline Client side scripting & 142 & $46 \%$ \\
\hline Client side scripting products & 35 & $11 \%$ \\
\hline Server side scripting & 219 & $70 \%$ \\
\hline Server side scripting products & 31 & $10 \%$ \\
\hline Programming languages & 212 & $68 \%$ \\
\hline Programming products & 32 & $10 \%$ \\
\hline Database & 172 & $55 \%$ \\
\hline Database products & 171 & $55 \%$ \\
\hline Operating systems & 103 & $33 \%$ \\
\hline Methodology & 113 & $36 \%$ \\
\hline General server experience & 72 & $23 \%$ \\
\hline General networking skills & 23 & $7 \%$ \\
\hline General e-commerce skills & 45 & $11 \%$ \\
\hline
\end{tabular}


Weaving a Web Development Curriculum

One hundred and sixty (51\%) of the positions requested experience with one or more markup languages. Table 3 summarizes the specific skills requested. Experience with HTML was by far the most requested skill $(91 \%)$. Additionally, many of the position announcements implied a requirement of understanding HTML (i.e. a request was made for JavaScript but not HTML; without a knowledge of HTML it would not be possible to embed JavaScript code into an HTML document).

Table 3. Markup Languages (N = 160, $\mathbf{P = 5 1 \% )}$
\begin{tabular}{|l|r|r|}
\hline \multicolumn{1}{|c|}{ Language } & \multicolumn{1}{c|}{$\mathbf{n}$} & \multicolumn{1}{c|}{$\%$} \\
\hline HTML & 145 & $91 \%$ \\
\hline DHTML & 38 & $24 \%$ \\
\hline UML & 9 & $6 \%$ \\
\hline
\end{tabular}

Thirty-four (11\%) of the positions requested experience with one or more basic web authoring software products. Table 4 summarizes the specific skills requested. Note that only $11 \%$ of the positions requested experience with a Web Authoring tool. The author's interpretation is that employers want hard coding experience and they will train employees to use the specific product tools. The most requested tool for positions requesting a Web authoring tool was Photoshop (65\%).

Table 4. Web Authoring Tools ( $N=34, P=11 \%)$

\begin{tabular}{|l|r|r|}
\hline \multicolumn{1}{|c|}{ Product } & \multicolumn{1}{c|}{ n } & \multicolumn{1}{c|}{$\%$} \\
\hline Photoshop & 22 & $65 \%$ \\
\hline Flash & 15 & $44 \%$ \\
\hline FrontPage & 10 & $29 \%$ \\
\hline
\end{tabular}

One hundred and forty-two (46\%) of the positions requested experience with one or more client side scripting languages. Table 5 summarizes the specific skills requested. JavaScript was the most requested skill (85\%), followed by VBScript (40\%). 
Table 5. Client Side Scripting ( $N=142, P=46 \%)$

\begin{tabular}{|l|r|r|}
\hline \multicolumn{1}{|c|}{ Language } & \multicolumn{1}{c|}{ n } & \multicolumn{1}{c|}{ \% } \\
\hline JavaScript & 121 & $85 \%$ \\
\hline VBScipt & 57 & $40 \%$ \\
\hline CSS & 23 & $16 \%$ \\
\hline XSL & 15 & $11 \%$ \\
\hline XSLT & 8 & $6 \%$ \\
\hline Generic* & 4 & $3 \%$ \\
\hline * client side scripting required but no specific language given. \\
\hline
\end{tabular}

Only thirty-five (11\%) of the positions requested experience with one or more client side scripting products. Again, the authors believe the employers are more interested in employees entering the position with solid programming skills rather than experience with scripting products. WebLogic (77\%) was the most requested skill. Table 6 summarizes the specific skills requested.

Table 6. Client Side Scripting Products ( $N=35,11 \%)$

\begin{tabular}{|l|r|r|}
\hline \multicolumn{1}{|c|}{ Product } & \multicolumn{1}{c|}{ n } & \multicolumn{1}{c|}{$\%$} \\
\hline WebLogic & 27 & $77 \%$ \\
\hline DreamWeaver & 8 & $23 \%$ \\
\hline Generator & 1 & $1 \%$ \\
\hline
\end{tabular}

Two hundred and nineteen (70\%) of the positions requested experience with one or more server side scripting languages. Experience with Active Server Pages was the most requested skill (66\%), followed by JSP/EJB (30\%). Table 7 summarizes the specific skills requested. 
Table 7. Server Side Scripting ( $N=219, P=70 \%)$

\begin{tabular}{|l|r|r|}
\hline \multicolumn{1}{|c|}{ Language } & \multicolumn{1}{c|}{ n } & \multicolumn{1}{c|}{$\%$} \\
\hline ASP/ASP.net & 145 & $66 \%$ \\
\hline JSP/EJB & 65 & $30 \%$ \\
\hline Perl & 39 & $18 \%$ \\
\hline Servlets & 24 & $11 \%$ \\
\hline CGI (generic) & 24 & $11 \%$ \\
\hline
\end{tabular}

Thirty-one (10\%) of the positions requested experience with one or more server side scripting products. Table 8 summarizes the specific skills requested. Cold Fusion (71\%) was the most requested product.

Table 8. Server Side Scripting Products ( $=31, P=10 \%)$

\begin{tabular}{|l|r|r|}
\hline \multicolumn{1}{|c|}{ Product } & \multicolumn{1}{c|}{ n } & \multicolumn{1}{c|}{$\%$} \\
\hline Cold Fusion & 22 & $71 \%$ \\
\hline InterDeveloper & 12 & $39 \%$ \\
\hline ISAPI & 4 & $13 \%$ \\
\hline NSAPI & 2 & $6 \%$ \\
\hline
\end{tabular}

Two hundred and twelve (68\%) of the positions listed one ore more programming languages. Table 9 shows the specific languages requested. Java (63\%) was the most requested language, followed by Visual Basic (50\%) and $\mathrm{C} / \mathrm{C}++(22 \%)$. 
Table 9. Programming Languages ( $N=212, P=68 \%)$

\begin{tabular}{|l|r|r|}
\hline \multicolumn{1}{|c|}{ Language } & \multicolumn{1}{c|}{ n } & \multicolumn{1}{c|}{$\%$} \\
\hline Java & 133 & $63 \%$ \\
\hline Visual Basic & 107 & $50 \%$ \\
\hline C/C++ & 47 & $22 \%$ \\
\hline Active X & 9 & $4 \%$ \\
\hline COBOL & 1 & $0 \%$ \\
\hline
\end{tabular}

Thirty-two (10\%) of the positions listed a programming product/development tool. Table 10 summarizes the programming language products required/requested. Visual InterDeveloper (50\%) was the most requested skill.

Table 10. Programming Products ( $=32, P=10 \%)$

\begin{tabular}{|l|r|r|}
\hline \multicolumn{1}{|c|}{ Product } & \multicolumn{1}{c|}{ n } & \multicolumn{1}{c|}{ \% } \\
\hline Visual InterDeveloper & 16 & $50 \%$ \\
\hline Visual Studio & 11 & $34 \%$ \\
\hline Visual Age & 6 & $19 \%$ \\
\hline Jbuilder & 4 & $13 \%$ \\
\hline
\end{tabular}

One hundred and seventy-two (55\%) of the positions requested one or more database skills. XML (56\%) and SQL (44\%) were the most requested skills. Table 11 summarizes the specific skills requested.

Table 11. Database ( $N=172, P=55 \%)$

\begin{tabular}{|l|r|r|}
\hline \multicolumn{1}{|c|}{ Language } & \multicolumn{1}{c|}{ n } & \multicolumn{1}{c|}{$\%$} \\
\hline XML & 96 & $56 \%$ \\
\hline SQL & 75 & $44 \%$ \\
\hline Generic & 34 & $20 \%$ \\
\hline ODBC & 8 & $5 \%$ \\
\hline
\end{tabular}


One hundred and seventy-one (55\%) of the positions listed a specific database product. Oracle (53\%) was the most requested skill, followed by SQL Server (36\%). Table 12 summarizes the database products required/requested.

Table 12. Database Products ( $=171, P=55 \%)$

\begin{tabular}{|l|r|r|}
\hline \multicolumn{1}{|c|}{ Product } & \multicolumn{1}{c|}{ n } & \multicolumn{1}{c|}{ \% } \\
\hline Oracle & 90 & $53 \%$ \\
\hline SQL Server & 61 & $36 \%$ \\
\hline MS Access & 25 & $15 \%$ \\
\hline MS Transaction SQL & 21 & $12 \%$ \\
\hline Sysbase & 18 & $11 \%$ \\
\hline DB2 & 11 & $8 \%$ \\
\hline Sysbase & 12 & $2 \%$ \\
\hline Informix & 3 & $2 \%$ \\
\hline Powerbuilder & 1 & $1 \%$ \\
\hline
\end{tabular}

One hundred and three (33\%) of the positions requested experience with one or more operating systems. Experience with Windows was required by 63 of employers, followed by $49 \%$ requiring UNIX. Table 13 summarizes the operating systems requested.

Table 13. Operating Systems ( $N=103, P=33 \%)$

\begin{tabular}{|l|r|r|}
\hline \multicolumn{1}{|c|}{ Operating system } & \multicolumn{1}{c|}{ n } & \multicolumn{1}{c|}{$\%$} \\
\hline Windows & 65 & $63 \%$ \\
\hline UNIX & 50 & $49 \%$ \\
\hline Sun Solaris & 10 & $10 \%$ \\
\hline Linux & 10 & $10 \%$ \\
\hline OS400 & 6 & $6 \%$ \\
\hline Mac OS & 1 & $1 \%$ \\
\hline
\end{tabular}


One hundred and thirteen $(36 \%)$ of the positions requested experience with one or more methodologies. Table 14 summarizes the operating systems requested.

Table 14. Methodology ( $N=113, P=36 \%)$

\begin{tabular}{|l|r|r|}
\hline \multicolumn{1}{|c|}{ Methodology } & \multicolumn{1}{c|}{ n } & \multicolumn{1}{c|}{ \% } \\
\hline COM/DCOM & 47 & $42 \%$ \\
\hline OOP/OOD & 34 & $30 \%$ \\
\hline Database Design & 31 & $27 \%$ \\
\hline Systems A\&D/SDLC & 27 & $24 \%$ \\
\hline RAD/JAD & 6 & $5 \%$ \\
\hline Mac OS & 1 & $1 \%$ \\
\hline
\end{tabular}

Seventy-two $(23 \%)$ of the positions requested experience with one or more servers. Table 15 summarizes the server program knowledge requests.

Table 15. Servers ( $N=72, P=23 \%)$

\begin{tabular}{|l|r|r|}
\hline \multicolumn{1}{|c|}{ Server } & \multicolumn{1}{c|}{ n } & \multicolumn{1}{c|}{$\%$} \\
\hline IIS & 41 & $57 \%$ \\
\hline WebSphere & 19 & $26 \%$ \\
\hline Apache & 10 & $14 \%$ \\
\hline MS Commerce & 7 & $10 \%$ \\
\hline
\end{tabular}

General networking skills were requested for $23(7 \%)$ of the positions. E-commerce experience was requested in $45(11 \%)$ of the positions.

\section{Existing Programs}

The higher education system realized the importance of the Web related jobs and positions. Universities and colleges started to develop their degree and certification programs to support students and the industry. Programs are available at MS level (e.g. Golden Gate University, CA), but most are BS degrees in the Applied Science field (e.g. Lewis-Clark State College, ID; North Seattle Community College, WA; West Valley College, CA). The programs are based on 35-50 credit units. 
Several professional organizations offer different certifications on the Web field. The Computer Training

Schools have CIW certifications (covering development, design, administration, security, networking, and e-commerce). The Web area is part of the MCSE certification series. Novell supports the use of their Web services with related programs. The Web is part of the CompTIA I-Net+ examination. Several universities and colleges offer certifications in the Web field including Java programming, HTML/Web page development, Web site management. The World Organization of Webmasters teamed up with colleges and businesses, who teach courses in various areas to offer Web related certifications. Almost 100 organizations in the US and Canada teach the WOW courses with the support of corporate partners. They use Prentice Hall books in their program.

\section{A Proposed Model Curriculum}

\section{A Model for a Certificate Web Page Development}

The analysis of the job advertisements suggested that a proposed program should include at a minimum courses from the following areas: communications basics, HTML/Web page design, Web programming, database applications, visual design, and site administration. Certainly each area can be covered several different ways and at different levels. Communication might include the whole networking area, Web pages can be extended with DHTML features, combined with Cascading Style Sheets and scripting with Javascript and/or VBScript. Database applications might include the integration of the Web platform with various database systems, allowing also information exchange across applications and platforms, application of data integration, manipulation and transformation by using XML/XSL tools. The Web programs can be developed for the user side in Java, VB, for the server side in Perl, C, Java, and ASP. The business requirements include transaction processing, payment handling, dynamic content delivery, and integration of additional application services. Visual design is beyond the general IS education, and involves artistic work, interface design, psychology, and the study of human and consumer behavior. The site administration background shall make sure that the services are up running, they are configured properly, they are an integral part of the organization's information services, and they handle the load and the requests of the users.

Keeping these areas and requirements in mind we proposed a Web Development certification program that includes courses from the mentioned areas, and gives the students a broad overview of the involved techniques and technologies.

The certificate program is designed to prepare students for web development positions, help with career changes, and give a broader view of Web technology. Current market conditions and the growing demand for information technology professionals require IS specialists with the experience and skill sets needed to design, create Web sites, and operate Web services. They have to manage Internet services, deal with design, operation and security issues, support their users, and fulfill system administrative tasks. This certificate will prepare a student to design and develop web pages, to use JavaScript to generate dynamic Web content, to understand and use Web programming solutions, to integrate Web solutions into the organization's information system, and to design and perform Web site administration tasks.

The certificate will prepare a student to design and develop web pages, to use appropriate scripting language to generate dynamic Web content, to integrate Web solutions into the organization's information system, and to design and perform Web site administration tasks.

CIS3xxx Web Page Development (HTML, CSS, Javascript, DHTML)................... 3

CIS3xxx Database Management Systems (terminology, design, theory, SQL) ......... 3 
CIS3xxx Business Application Development w/ Visual Basic

or

CIS3xxx Business Application and Web Applet Design w/ Java............................. 3

CIS3xxx Telecommunication Systems .......................................................... 3

CIS4xxx Web Site Administration ....................................................................... 3

There are two prerequisite courses (CIS 2xxx - Computer Applications for Business and CIS 2xxx Business Problem Solving: A Structured Programming Approach) that give the general business computing and problem solving background to the program.

\section{A Model for a 4 year degree in Computer Information Systems, with an Emphasis Area in Web Development.}

The degree will prepare a student to design and develop web sites, to use appropriate programming languages to generate dynamic Web content, to integrate Web solutions into the organization's information system, and to design and perform network and Web site administration tasks. The degree is intended to give students a solid background of conceptual knowledge in Web page design and development, clientside and server-side programming, general networking, database design and application development, multimedia programming, and service administration that will allow them to keep pace in a fast-changing and dynamic field. Upon completion of the degree the student will be prepared for careers that involve website design, service and application development, and site maintenance, as well as more businessoriented careers such as business project managers. The degree is applicable for students in most of the Web related fields. Graduates from this degree can expect to find jobs with companies, system providers, consulting firms or individuals.

\begin{tabular}{|c|c|}
\hline $\mathrm{XXX}$ & ations for Business (basics of business computing) \\
\hline CIS2xxx & usiness Problem Solving (general problem solving techniques) \\
\hline CIS3Xxx & 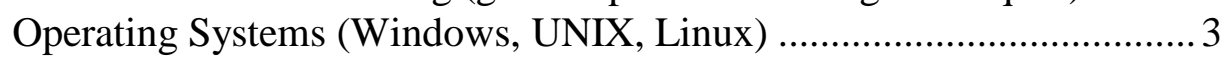 \\
\hline IS $3 x x x$ & Web Page Development (HTML, CSS, Javascript, DHTML). \\
\hline CIS3xxx & Database Management Systems (terminology, design, theory, SQL) ..... 3 \\
\hline CIS3xxx & Application Development w/ Visual Basic . \\
\hline CIS3xxx & Application and Web Applet Design w/ Java.. \\
\hline CIS3Xxx & Programming in Perl and/or $\mathrm{C} / \mathrm{C}++\ldots \ldots \ldots \ldots . . . .$. \\
\hline CIS3xxx & ia Information Systems (cre \\
\hline CIS3xxx & n Systems (networking basics) \\
\hline CIS4xxx & s (database applic \\
\hline CIS4xxx & $\mathrm{k}$ Installation and Administration (intranet administration) .... \\
\hline CIS4xxx & e Administration (configuring and running Web services) .... \\
\hline CIS4xxx & Advanced Server Side Programming (servlets, ASP, JSP). \\
\hline CIS4xxx & Inte \\
\hline CIS4xxx & ystems Analysis and Design \\
\hline
\end{tabular}

\section{Summary And Conclusion}

It is clear that the web development jobs mean a new and approaching information systems area. The titles and the content are sweeping, and the roles fluctuate, contrast, diverge, and vary as the companies' needs 
differ. It also seems to have a close relationship to the level of the recent Web applications in the company's information systems. The broad spectrum, the very different job descriptions and advertisements suggest that those businesses who just started their Web development might be satisfied with less skills and knowledge, and those who have already established a solid Web presence might have higher expectations, and require more experience and higher, more complex skills. But the fact is that technical specialists, content designers, and also managers need a broad vision of the Web, the applicable tools, and the involved areas. They all need to understand the vital pieces of the Web services, be familiar with the processes, and make the right decisions regarding the technologies, infrastructure, and development. Higher Education can support businesses by offering regular courses and creating certification and degree programs that fulfill industry needs.

\section{References}

Mozilla.org (2002) "Web Developer Documentation" (January 17, 2002) Accessed March 10, 2002 at http://www.mozilla.org/docs/web-developer/indexd.htm

U.S. Bureau of Labor Statistic (2001) "Occupational Employment Statistics", 2000 National Occupational Employment and Wage Estimates, Computer and Mathematical Occupations (Nov. 15, 2001) Accessed March 10, 2002 at http://Www.bIs.gov/oes/2000/oes 15Co.htm

U.S. Department of Labor (2001)" New and emerging occupations"(December, 2001) Accessed March 10, 2002 at http://WwW.bIs.gov/opub/1s/pdt/opbils45.pdt

Web Developer's Journal. http://www.webdevelopersjournal.com

\section{Other Resources}

\section{Government:}

Occupational Employment Statistics. Bureau of Labor Statistics. Occupational. Employment Statistics. Internet: http://stats.bls.gov/

\section{Organizations:}

America's Career InfoNet. Employability Profile. Internet: www. acinet.org

Association for Computer Machinery (ACM). Internet: www.info.acm.org

Computer Jobs \& Technical Employment in the US \& Canada. Internet: www.computerwork.com

HTML Writers Guild. Internet: www.hwg.org

IEEE Computer Society. Internet: www.computer.org

Institute for the Certification of Computer Professionals. Internet: www.iccp.org

Institute of Electrical and Electronics Engineers. Internet: www.ieee.org

International Webmasters Association. Internet: www.iwanet.org

Internet Society. Internet: www.isoc.org

World Organization of Webmasters. Internet: www.joinwow.org

\section{Biography}

Wayne A. Haga, Ph.D, in Applied Statistics from the University of Northern Colorado, MS in Computer Science from North Dakota State University. Areas of research interest include project management, 
evaluation of online courses, and curriculum issues. Dr. Haga primarily teaches courses in database design and development courses, as well as programming languages.

János T. Füstös, dr. univ., MS Chem. Eng., both from the University of Veszprém, (Hungary). Major research area includes the comparative study of information systems in managerial decisions at international level. Dr. Füstös primarily teaches courses in Web page development and Web site administration. 